\title{
ORIGINAL ARTICLE \\ Traumatic spinal cord injury in Botswana: characteristics, aetiology and mortality
}

\author{
I Löfvenmark ${ }^{1}$, C Norrbrink ${ }^{1,2}$, L Nilsson-Wikmar ${ }^{1}$, C Hultling ${ }^{1,3}$, S Chakandinakira ${ }^{4}$ and M Hasselberg ${ }^{5}$
}

Study design: Descriptive study with a cross-sectional design.

Objectives: To describe the epidemiology of traumatic spinal cord injuries (TSCls) in Botswana, with a specific focus on road traffic crashes (RTC).

Setting: Main public referral hospital, Gaborone, Botswana.

Method: Two samples were included. Sample one described the epidemiology and included patients admitted during a 2-year period with acute TSCI. Sample two included only patients with TSCI due to RTC.

Results: Annual incidence was 13 per million population. Epidemiology of TSCl: 49 patients were included, $71 \%$ male, age ranging from 4 to 81 years, $80 \% \leqslant 45$ years. Tetraplegia was more common than paraplegia (59/41\%), and 39\% had C1-C4 level of injury. The main cause of TSCI was RTC (68\%), followed by assault (16\%) and falls (10\%). Mortality was $20 \%$, where all, but one, had tetraplegia (18\%). Median time from injury to spinal surgery was 12 days, with longer time for women, 16 days compared with 8 for men. Burst tire was the primary cause of RTC resulting in a TSCl, followed by hitting animals on the road. The majority had been passengers and $72 \%$ were involved in single crashes.

Conclusion: The most common cause for TSCI was RTC, followed by assault. In-hospital mortality was high and the waiting period from the time of accident to spinal surgery was long, especially for women. The aetiology and high mortality of TSCl in Botswana indicate that improvements in roadway safety and medical care may decrease the TSCI incidence and mortality.

Spinal Cord (2015) 53, 150-154; doi:10.1038/sc.2014.203; published online 25 November 2014

\section{INTRODUCTION}

The incidence of traumatic spinal cord injury (TSCI) varies widely between countries. The global annual estimate is 15-40 per million population with a mean of $23 .^{1,2}$ There is a lack of data on the incidence of TSCI in low- and middle-income countries. ${ }^{2,3}$ From SubSaharan African countries, annual incidences of 21-29 per million population have been reported. ${ }^{2}$

TSCI occurs mainly in young-to-middle-aged populations, ${ }^{1,3-6}$ and males constitute $63-88 \%$ in low/middle-income countries and 75 $80 \%$ in high-income countries. ${ }^{1}$ From Sub-Saharan African countries, the male dominance has been reported to be up to $92 \% .^{3,7}$

Historically, road traffic crashes (RTC) have been the leading cause of TSCI globally. ${ }^{6}$ In some high-income countries, fall injuries have increased with ageing of the population and constitute the primary cause of TSCI. ${ }^{6}$ In many Sub-Saharan African countries, RTC is still the leading cause. ${ }^{3,5,7}$ There are, however, exceptions with violence in South Africa, ${ }^{8,9}$ falls in Senegal ${ }^{10}$ and collapsing tunnels in one part of Nigeria being common reasons. ${ }^{11}$

Acute mortality has, with increased availability and quality of specialised care and acute transportation, decreased to almost zero in parts of the industrialised world. ${ }^{12}$ From Sub-Saharan Africa, two studies from Nigeria reported mortality rates of $17.5 \%$ and $26 \%$, respectively, during acute hospitalisation, ${ }^{5,11} 29 \%$ in Sierra Leone, ${ }^{13}$ while $7.5 \%$ was reported from Zimbabwe. ${ }^{3}$

Botswana has a history that differs from most African countries, changing swiftly from being one of the poorest countries to becoming a middle-income country, with a relatively well-developed health-care system. Similar to the majority of low/middle-income countries, Botswana lacks reliable information on clinical characteristics, mortality and aetiology of TSCI; all of those being important factors in promoting prevention. The aim of this study was therefore to describe the epidemiology of TSCI, focussing specifically on transport-related injuries.

\section{MATERIALS AND METHODS}

Setting and study population

This study was conducted at the major public referral hospital in Botswana, Princess Marina Hospital (PMH). A specialised SCI-rehabilitation centre was recently established at the hospital, where patients are admitted when medically stable.

Two samples of patients were included. Sample one, used to describe the epidemiology of TSCI, comprised 52 patients with acute TSCI admitted from 1 February 2011 to 31 January 2013. Three women were excluded from analysis as they did not sign the consent form; consequently, 49 persons were included. Sample two was used to specifically study RTC and included 33 patients with

${ }^{1}$ Department of Neurobiology, Care Sciences and Society, NVS, Karolinska Institutet, Stockholm, Sweden; ${ }^{2}$ Department of Clinical Sciences, Karolinska Institutet, Danderyd Hospital, Stockholm, Sweden; ${ }^{3}$ Department of Neuroscience, Karolinska Institutet, Stockholm, Sweden; ${ }^{4}$ Spinalis Botswana SCI-Rehabilitation Project, Gaborone, Botswana and ${ }^{5}$ Department of Public Health Sciences, Karolinska Institutet, Stockholm, Sweden

Correspondence: I Löfvenmark, Spinalis, Rehab Station Stockholm, Department of Neurobiology, Care Sciences and Society, NVS, Karolinska Institutet, Frosundaviks allé 13, Stockholm 11733, Sweden.

E-mail: inka@spinalis.se

Received 22 November 2013; revised 14 September 2014; accepted 15 October 2014; published online 25 November 2014 
road traffic injuries from sample one together with 50 persons living with chronic TSCI due to RTC before 2011. These persons were identified by the Motor Vehicle Accident Fund, insurance companies and health services and were assessed as outpatients.

\section{Variables}

All patients were assessed with respect to neurological levels and completeness of injury. Information about socio-demography, clinical characteristics, circumstances and cause of injury, mode of transportation from the site of injury, associated injuries, spinal surgery and premedical history was also collected. Outcome measures used were mainly derived from work by the International Spinal Cord Society ${ }^{14-16}$ complemented with socio-demographic information and comorbid diagnoses.

\section{Data analysis}

Descriptive statistics with frequencies and cross-tables were compiled using the IBM Statistical Package for the Social Sciences (SPSS) Statistics (Version 21, IBM, SPSS, New York, NY, USA). Clinical and demographic characteristics and injury-related data were analysed in the first sample $(n=49)$. Separate analyses were conducted for in-hospital mortality as well as for living circumstances of patients referred to the SCI-rehabilitation centre. The second sample was analysed with respect to aetiology of RTC $(n=83)$. Differences between gender and time from injury event to surgery were analysed using the Wilcox ranksum test. $P$-value for statistical significance was set to $P<0.05$.

\section{Ethics}

The ethical committee at the Ministry of Health in Botswana (PPME: 13/18/1 Vol VIII (92)) and at PMH (PMH 5/79 (27a)) approved the study.

\section{RESULTS}

\section{Epidemiology of TSCI}

Incidence. With a population of 2 million $^{17}$ and the 52 newly injured people with TSCI during the 2-year study period, the estimated annual incidence was 13 per million population. The annual incidence of TSCI surviving to be discharged home from rehabilitation was 10 per million population.

Characteristics. The majority of those injured were men (71\%); 80\% were aged $\leqslant 45$ years, and two were children (Table 1 ). Tetraplegia was more common than paraplegia, with high cervical lesions (C1-4) constituting 39\%; 61\% had a motor complete injury (Table 2). Table 3 presents the living conditions and the level of education for patients referred to the SCI-rehabilitation centre, showing that the majority of patients lived in houses with electricity and water but with pit-latrine and traditional baths, essentially oval-shaped basins substituting for bathtubs.

Associated injuries and spinal surgery. Comorbid diagnoses (missing data $=9)$ included HIV $(n=6)$ and hypertension $(n=2)$.

Associated injuries (missing data $=5)$ were present in 33\% $(n=16)$ and included fractures in upper and lower extremities, as well as ribs, abdominal injuries and head trauma.

Thirty-five patients sustained vertebral injuries (missing data $=6$ ), 30 of whom underwent spinal surgery. The median time from injury to surgery was 12 days (interquartile range (IQR) 5-21); 10 patients underwent surgery within a week, and 19 within 2 weeks. The number of days between injury and spinal surgery were significantly higher $(P=0.04)$ for women (median 16, IQR 11-29) compared with men (median 8, IQR 3-18).

Transportation. Transport from the site of injury to the emergency unit or local clinic was by ambulance for $20 \%$ of the patients, while $43 \%$ were transported in private cars, by the police or by government
Table 1 Characteristics of patients with acute traumatic spinal cord injury admitted from 1 February 2011 to 31 January 2013, demographic and clinical

\begin{tabular}{|c|c|c|}
\hline & $\mathrm{n}$ & $\%$ \\
\hline \multicolumn{3}{|l|}{ Gender } \\
\hline Male & 35 & 71 \\
\hline Female & 14 & 29 \\
\hline \multicolumn{3}{|l|}{ Age at injury, years } \\
\hline $0-15$ & 2 & 4 \\
\hline $16-30$ & 18 & 37 \\
\hline $31-45$ & 19 & 39 \\
\hline $46-60$ & 7 & 14 \\
\hline $61-75$ & 1 & 2 \\
\hline $76+$ & 1 & 2 \\
\hline Missing data & 1 & 2 \\
\hline \multicolumn{3}{|l|}{ Cause of injury } \\
\hline RTC & 33 & 68 \\
\hline Assault/violence related & 8 & 16 \\
\hline Fall & 5 & 10 \\
\hline Sport & 1 & 2 \\
\hline Struck by objects & 2 & 4 \\
\hline
\end{tabular}

Abbreviation: RTC, road traffic crashes.

Table 2 Level and completeness of injury for patients admitted with acute traumatic spinal cord injury from 1 February 2011 to 31 January 2013

\begin{tabular}{lcccc}
\hline & $A I S A+B$ & $A / S C+D$ & Missing AIS & $\begin{array}{c}\text { Total } \\
\end{array}$ \\
& $\mathrm{n}$ & $\mathrm{n}$ & $\mathrm{n}$ & $\mathrm{n}(\%)$ \\
\hline Cervical 1-4 & 7 & 6 & 6 & $19(39)$ \\
Cervical 5-8 & 6 & 3 & 1 & $10(20)$ \\
Thoracic 1-6 & 11 & 0 & 0 & $11(23)$ \\
Thoracic 7-12 & 5 & 1 & 1 & $7(14)$ \\
Lumbar & 1 & 1 & 0 & $2(4)$ \\
Total, $n$ (\%) & $30(61)$ & $11(23)$ & $8(16)$ & $49(100)$
\end{tabular}

Abbreviation: AIS, American Spinal Injury Association (ASIA) Impairment Scale, tested at admission.

vehicles designated to the clinics. One person was transported by a truck and one by a donkey cart (unknown or missing data $=33 \%$ ). Ambulances were used in almost all cases for transfers from the first clinic or local hospital to a referral hospital. Eight patients were transported straight to a referral hospital where spinal stabilisation was done or straight to $\mathrm{PMH}$. Twenty-three patients were transported to one additional medical facility with up to four transportations before reaching the appropriate level of hospital care. No association was found between mode and the number of transports and completeness of injury.

Cause of injury. The most common cause of injury was RTC $(n=33$; $68 \%)$, with 31 cases $(63 \%)$ involving motorised vehicles and two involving donkey carts (Table 1). A further analysis of RTC was conducted and is described in a special section below. Violence-related injuries were mainly stabbings $(n=5)$, while gunshot, assault and purposely hit by a car were other causes. Most fall injuries were work related $(n=4)$ : from heights such as rooftops during construction $(n=1)$, electrical poles $(n=2)$ or scaffolding $(n=1)$, and one person 
Table 3 Socio-demographic data for patients referred to the spinal centre $(n=39)^{\mathrm{a}}$

\begin{tabular}{|c|c|c|}
\hline & $\mathrm{n}$ & $\%$ \\
\hline \multicolumn{3}{|l|}{ Marital status } \\
\hline Single & 20 & 51 \\
\hline Married & 8 & 21 \\
\hline Cohabiting & 3 & 8 \\
\hline In a relationship & 6 & 15 \\
\hline Child & 2 & 5 \\
\hline \multicolumn{3}{|l|}{ Living circumstances } \\
\hline Alone & 3 & 8 \\
\hline Live with parents/siblings & 19 & 48 \\
\hline Own family, married & 8 & 20 \\
\hline Cohabiting & 3 & 8 \\
\hline Relatives & 5 & 13 \\
\hline Friends & 1 & 3 \\
\hline \multicolumn{3}{|l|}{ Housing } \\
\hline With water and electricity & 28 & 72 \\
\hline With water or electricity & 3 & 8 \\
\hline Without water or electricity & 4 & 10 \\
\hline Mud house & 3 & 8 \\
\hline Missing & 1 & 2 \\
\hline \multicolumn{3}{|l|}{ Toilet } \\
\hline Toilet inside & 13 & 33 \\
\hline Toilet outside & 2 & 5 \\
\hline Pit latrine & 23 & 59 \\
\hline Missing & 1 & 3 \\
\hline \multicolumn{3}{|l|}{ Bath } \\
\hline Shower/bath inside & 15 & 38 \\
\hline Traditional bath & 21 & 54 \\
\hline Missing & 3 & 8 \\
\hline \multicolumn{3}{|l|}{ Education level } \\
\hline University & 3 & 8 \\
\hline Tertiary education & 6 & 15 \\
\hline Secondary school & 18 & 46 \\
\hline Primary school & 6 & 15 \\
\hline No school & 3 & 8 \\
\hline Child & 2 & 5 \\
\hline Missing data & 1 & 3 \\
\hline
\end{tabular}

falling from a tree. All assault injuries, except one, were in the age group 16-30 years, while RTC's were overrepresented in the age group 31-45 years (Figure 1).

In-hospital mortality, demography and clinical characteristics. The mortality rate was $20 \%(n=10)$ prior to being referred to the SCIrehabilitation centre. The median age of deceased patients was 34 years (Table 4). These people lived for 2-50 days after TSCI, with a mean survival of 28 days. Eight of the 10 deceased patients had been transferred to other clinics or hospitals before admission to an appropriate referral hospital or $\mathrm{PMH}$; a total of eight patients, however, arrived within 1 day after injury.

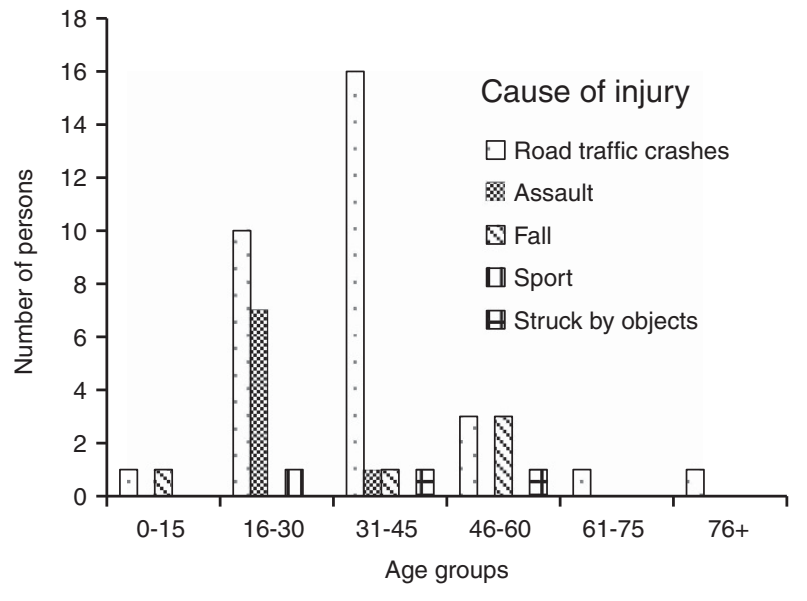

Figure 1 Cause of TSCls by age groups.

Table 4 Characteristics of deceased patients $(n=10)$

\begin{tabular}{|c|c|}
\hline & $n$ \\
\hline \multicolumn{2}{|l|}{ Gender } \\
\hline Male & 9 \\
\hline Female & 1 \\
\hline \multicolumn{2}{|l|}{ Age at injury, years } \\
\hline$\leqslant 15$ & 0 \\
\hline $16-30$ & 2 \\
\hline $31-45$ & 5 \\
\hline $46-60$ & 1 \\
\hline $61-75$ & 0 \\
\hline$\geqslant 76$ & 1 \\
\hline Missing data & 1 \\
\hline \multicolumn{2}{|l|}{ Level of injury } \\
\hline Tetraplegia C1-4a & 8 \\
\hline Tetraplegia C5-8 & 1 \\
\hline Paraplegia & 1 \\
\hline \multicolumn{2}{|l|}{ Cause of injury } \\
\hline RTC & 9 \\
\hline Fall & 1 \\
\hline
\end{tabular}

\section{Road traffic crashes}

Characteristics of participants with road traffic injuries (sample two) are shown in Table 5. Thirty-three newly injured from sample one and 50 persons living with a chronic TSCI due to a RTC were included. The median time since injury for those with a chronic TSCI was 7.5 years (IQR 3-12).

The self-reported causes of RTC (Table 6) were primarily burst tires, followed by trying to avoid or hitting cows or donkeys on the road. There were 60 cases of single crashes (72\%) (including two donkey carts), 11 collisions with other cars (one motorbike-driver) and three were pedestrians (missing data $=9$ ).

Sixteen of the 23 drivers used seatbelts while 11 of the 41 passengers used seatbelts, 20 did not and 10 were passengers on pick-up trucks. No association was found between the reported use of seatbelts and the level and completeness of injury. 
Table 5 Characteristics of persons with traumatic spinal cord injury due to road traffic crashes

\begin{tabular}{|c|c|c|}
\hline & Acute $(n=33), n(\%)$ & Chronic $(n=50), n(\%)$ \\
\hline \multicolumn{3}{|l|}{ Gender } \\
\hline Male & $21(64)$ & $30(60)$ \\
\hline Female & $12(36)$ & $20(40)$ \\
\hline \multicolumn{3}{|c|}{ Age at injury, years } \\
\hline$\leqslant 15$ & $1(3)$ & $1(2)$ \\
\hline $16-30$ & $10(30)$ & $30(60)$ \\
\hline $31-45$ & $16(49)$ & $16(32)$ \\
\hline $46-60$ & $3(9)$ & $3(6)$ \\
\hline $61-75$ & $1(3)$ & 0 \\
\hline$\geqslant 76$ & $1(3)$ & 0 \\
\hline Missing data & $1(3)$ & 0 \\
\hline \multicolumn{3}{|l|}{ Level of injury } \\
\hline Tetraplegia & $22(67)$ & $11(22)$ \\
\hline $\mathrm{C} 1-4$ & $15(46)$ & $8(16)$ \\
\hline C5-8 & $7(21)$ & $3(6)$ \\
\hline Paraplegia & $11(33)$ & $39(78)$ \\
\hline Thoracic & $11(33)$ & $38(76)$ \\
\hline Lumbar & 0 & $1(2)$ \\
\hline \multicolumn{3}{|c|}{ Completeness of injury $(A / S)^{a}$} \\
\hline A & $19(58)$ & $34(68)$ \\
\hline $\mathrm{B}$ & $1(3)$ & $10(20)$ \\
\hline C & $2(6)$ & $5(10)$ \\
\hline $\mathrm{D}$ & $4(12)$ & $1(2)$ \\
\hline Missing data & $7(21)$ & 0 \\
\hline
\end{tabular}

aAIS, American Spinal Injury Association (ASIA) Impairment Scale, tested at admission for acute injury and at first visit to SCl outpatient clinic for the chronic group.

Table 6 Causes of road traffic crashes by level of injury and gender

\begin{tabular}{|c|c|c|c|c|c|}
\hline Cause of RTC & $\begin{array}{c}\text { Tetraplegia } \\
\mathrm{n}\end{array}$ & $\begin{array}{c}\text { Paraplegia } \\
\mathrm{n}\end{array}$ & $\begin{array}{c}\text { Male } \\
\mathrm{n}\end{array}$ & $\begin{array}{c}\text { Female } \\
\mathrm{n}\end{array}$ & $\begin{array}{l}\text { Total } \\
\text { n (\%) }\end{array}$ \\
\hline Burst tire & 8 & 12 & 11 & 9 & $20(24)$ \\
\hline Animal on the road & 5 & 6 & 9 & 2 & 11 (13.5) \\
\hline Overtaking & 1 & 6 & 3 & 4 & $7(8.5)$ \\
\hline Hit by another car & 1 & 6 & 3 & 4 & $7(8.5)$ \\
\hline Lost control & 1 & 6 & 2 & 5 & $7(8.5)$ \\
\hline Traffic violation ${ }^{a}$ & 2 & 4 & 4 & 2 & $6(7)$ \\
\hline Other causes ${ }^{b}$ & 8 & 6 & 11 & 3 & $14(17)$ \\
\hline Unknown & 7 & 4 & 8 & 3 & $11(13)$ \\
\hline Total, $n$ & 33 & 50 & 51 & 32 & $83(100)$ \\
\hline
\end{tabular}

Abbreviation: RTC, road traffic crashes.

aTraffic violations includes driving through red light, drunken or reckless driving.

bother causes includes mechanical fault, lost a tire, fell asleep, hit a pothole and fell off donkey carts.

\section{DISCUSSION}

This is, to the best of our knowledge, the first study on TSCI in Botswana and contributes new knowledge that can also be of importance for other low- and middle-income countries. The main findings of the study were that RTC was the leading cause of injury followed by violence. Estimated annual incidence was 13 per million population, and the calculated incidence for patient discharged from rehabilitation was 10 per million. Two out of the five sustained a high tetraplegia, and in-hospital mortality was high. The time between injury and spinal surgery was long, especially for women. In-depth analysis of RTC revealed burst tires to be the primary reason, and the majority were single-vehicle accidents.

The results regarding aetiology in this study are in accordance with most studies from Sub-Saharan countries, with RTC being the leading cause. ${ }^{3,5,7}$ The majority of highways are single lane, with high speed limits and no separation between the lanes or street lights. There was no information available regarding alcohol use as a factor contributing to TSCI.

Violence is the primary cause in some parts of neighbouring South Africa, ${ }^{7}$ especially due to gunshot wounds. ${ }^{8,9}$ In our study, stabbing was the primary form of violence, with only one gunshot injury. Previous studies from low- or middle-income countries have shown that fall injuries result predominantly from falling from trees or roofs. ${ }^{3,4}$ In Botswana, falls were mainly work related, including falls from electrical poles and rooftops during construction work.

Estimated annual incidence was lower than expected, based on anecdotal reports and should be seen as a rough estimate. We believe that there were unrecorded cases of TSCI in Botswana not included in this study. Survival bias might be present, and limitations are further discussed below.

The number of patients with tetraplegia is consistent with global reports of $32-75 \%$ tetraplegia. ${ }^{6}$ Studies reporting higher frequency of tetraplegia are mainly from high-income countries $(42-75 \%)^{1}$ and from China $(69-73 \%) .^{18}$ In low- and middle-income countries, paraplegia seems to be more common $(52-95 \%),{ }^{1,4}$ which is also reported from Sub-Saharan Africa (70-75\%). 5,8 This might be explained by high prehospital mortality with cervical injuries. C1-4 were the most common levels of injury, most likely contributing to the high in-hospital mortality rate. Nigeria and Sierra Leone have reported similar figures (17-29\%), 5,11,13 while lower figures have been presented from low- and middle-income countries, such as China and Zimbabwe (1.4-7.5\%). ${ }^{3,18}$ These low mortality rates are similar to many high-income countries such as, for instance, as low as $0 \%$ in Sweden. ${ }^{12}$ A factor contributing to the high in-hospital mortality may have been poor access to the intensive care unit.

There are several reasons available to explain the delayed spinal surgery, such as: occasional lack of neurosurgeons, lack of theatre space, extensive administrative work if the patient needed transfer to another hospital for surgery, prolonged stay at district hospitals due to lack of correct diagnosis, prolonged referral procedures, and lack of transportation. The only significant gender difference, with spinal surgery being more delayed for women, could not, however, be explained by the data at hand and the small sample size. The patients are cared for in separate male and female wards prior to surgery; however, they share physicians.

We could not detect any associations between transport and severity of injury, which could have been expected considering the number of long-distance transportations due to the size of the country and the distance between health-care facilities. The majority of patients were initially transported by vehicles other than ambulances from the accident site, sometimes in a sitting position and often by non-medical staff. Ambulances were available for the majority of onward transports. Since 2013, trauma boards and hard neck-collars are used in ambulances and, occasionally, spider harnesses as well. Prior to that, no formal equipment was organised in ambulances.

Poor car and road maintenance and the hot climate combined with long driving distances could be possible reasons for burst tires, the single most common cause of TSCI in Botswana. The finding concerning hitting or avoiding animals on the road was less surprising as it has previously been reported as a common cause of RTC in 
Botwana $^{19}$ and many roads are not fenced to separate domestic animals. Travelling in a non-sedan vehicle carries a higher risk of TSCI. ${ }^{20}$ Seatbelts are mandatory in the front seats and are re-enforced; however, there is no legislation regarding the use of seatbelts in the back seats. There is also a need for legislations to decrease the common use of pick-up trucks for transportation. Road safety awareness is increasing in Botswana, and public information campaigns are common.

The prospective collection of the first sample is a strength of this study. The study was conducted at a national designated referral hospital for TSCI, where all newly injured patients with TSCI should be transferred. Additionally, data were collected by one team with a limited number of persons working together, thus facilitating reliability; validated international outcome measures were used for assessments. ${ }^{14-16}$

A number of limitations of the study need to be highlighted. First, we did not have access to prehospital data, which can lead to survival bias, and we had no data of acute mortality from rural hospitals. Possible explanations for unrecorded cases are the uncertainty of the referral system, that all newly injured were not referred to PMH and that the international procedure of defining an SCI is not in use at the rural hospitals, which probably led to missed diagnoses, especially regarding patients with motor incomplete injuries. In addition, there are private and mine hospitals that occasionally receive patients with TSCI, and before the SCI-centre was established, patients were often sent to South Africa for surgery and rehabilitation. Only a few patients were admitted from the north of the country. However, the majority of RTCs occur in the Gaborone area and along the main highway, ${ }^{19}$ and the fatality rate in traffic is high in Botswana, between 4 and 500 per year. ${ }^{19}$ Based on reports from the Motor Vehicle Accident Fund and contacts with other referral hospitals, we expect that the absolute majority of patients were transferred to $\mathrm{PMH}$.

Information regarding how and why the accident happened, the use of seatbelts and transport to the emergency centre was self-reported by the patients as documentation is limited. Parts of the data have been confirmed from the medical records, but it has been mainly up to the patients' discretion to share their information. We are aware that this can lead to reporting bias; however, self-reported data can, in this context, be seen both as a limitation and a strength. There is no reason to believe that patients will share incorrect information about the injury situation, with the exception of information that can influence insurance or sensitive information. Data are mainly missing for the deceased patients, as it was usually not possible to obtain this information from medical records.

In conclusion, the most common reason for TSCI in Botswana was RTC, followed by assault. The in-hospital mortality rate was $20 \%$, and the waiting period before spinal surgery was long. The aetiology and high mortality of TSCI in Botswana indicates that improvements in roadway safety and medical care may decrease TSCI incidence and mortality.

\section{DATA ARCHIVING}

There were no data to deposit.

\section{CONFLICT OF INTEREST}

The authors declare no conflict of interest.

\section{ACKNOWLEDGEMENTS}

We thank Dr Gureja for his experienced assistance and comments. We also thank the Swedish Neuro Association (NHR), the Swedish International Developmental Cooperation Agency (Sida) and the Spinalis Foundation for their financial support.

1 Chiu WT, Lin HC, Lam C, Chu SF, Chiang YH, Tsai SH. Review paper: Epidemiology of traumatic spinal cord injury: comparisons between developed and developing countries. Asia Pac J Public Health 2010; 22: 9-18.

2 Lee BB, Cripps RA, Fitzharris M, Wing P. The global map for traumatic spinal cord injury epidemiology: update 2011, global incidence rate. Spinal Cord 2014; 52: 110-116.

3 Levy LF, Makarawo S, Madzivire D, Bhebhe E, Verbeek N, Parry O. Problems, struggles and some success with spinal cord injury in Zimbabwe. Spinal Cord 1998; 36: 213-218.

4 Hoque F, Grangeon C, Reed K. Spinal cord lesions in Bangladesh: an epidemiological study 1994-1995. Spinal Cord 1999; 37: 858-861.

5 Obalum DC, Giwa SO, Adekoya-Cole TO, Enweluzo GO. Profile of spinal injuries in Lagos, Nigeria. Spinal Cord 2009; 47: 134-137.

6 van den Berg MEL, Castellote JM, Mahillo-Fernandez I, de Pedro-Cuesta J. Review: Incidence of spinal cord injury worldwide: a systematic review. Neuroepidemiology 2010; 34: 184-192.

7 Draulans N, Kiekens C, Roels E, Peers K. Review: Aetiology of spinal cord injuries in Sub-Saharan Africa. Spinal Cord 2011; 49: 1148-1154.

8 Hart C, Williams E. Epidemiology of spinal cord injuries: a reflection of changes in South African society. Paraplegia 1994; 32: 709-714.

9 Velmahos GC, Degiannis E, Hart K, Souter I, Saadia R. Changing profile in spinal cord injuries and risk factors influencing recovery after penetrating injuries. J Trauma Injury Infect Crit Care 1995; 38: 334-337.

10 Seye SIL, Sow CM, Bassene N, Gueye M, Pouye I. Traumatismes recents du rachis a propos de 496 cas, 30 necropsies. Med Tropicale 1993; 53: 471-477.

11 Igun GO, Obekpa OP, Ugwu BT, Nwadiaro HC. Spinal injuries in the plateau state Nigeria. East Afr Med J 1999; 76: 75-79.

12 Divanoglou A, Westgren N, Seiger Å, Hultling C, Levi R. Late mortality during the first year after acute traumatic spinal cord injury: a prospective, population-based study. J Spinal Cord Med 2010; 33: 117-127.

13 Gosselin RA, Coppotelli C. A follow-up study of patients with spinal cord injury in Sierra Leone. Int Orthop 2005; 29: 330-332.

14 DeVivo M, Biering-Sørensen F, Charlifue S, Noonan V, Post M, Stripling T et al. International Spinal Cord Injury DataCore Data Sets. Spinal Cord 2006; 44: 535-540.

15 Krassioukov A, Alexander MS, Karlsson AK, Donovan W, Mathias CJ, Biering-Sørensen F. International spinal cord injury cardiovascular function basic data set. Spinal Cord 2010; 48: 586-590.

16 Waring WP, Biering-Sorensen F, Burns S, Donovan W, Graves D, Jha A et al. 2009 review and revision of the International Standards for the Neurological Classification of Spinal Cord Injury. J Spine Cord Med 2010; 33: 346-352.

17 Trading Economics Botswana population. Available from http://www.tradingeconomics. com/botswana/population [accessed 29 March 2014].

18 Ning GZ, Yu TQ, Feng SQ, Zhou XH, Ban DX, Liu Y et al. Epidemiology of traumatic spinal cord injury in Tianjin, China. Spinal Cord 2011; 49: 386-390.

19 Motor Vehicle Accident Fund. Road Crash and Claims. Annual Report. MVA Fund House: Gaborone, Botswana. 2010, pp 15 and 20.

20 O'Connor PJ, Brown D. Relative risk of spinal cord injury in road crashes involving seriously injured occupants of light passenger vehicles. Accid Anal Prev 2006; 38 1081-1086. 